RESEARCH PAPER

\title{
If smoking increases absences, does quitting reduce them?
}

\author{
J L Sindelar, N Duchovny, T A Falba, S H Busch
}

Tobacco Control 2005;14:99-105. doi: 10.1136/tc.2003.005884

See end of article for authors' affiliations

......................

Correspondence to: Dr Tracy A Falba, PO Box 208034, New Haven, CT 06520-8034, USA; tracy.falba@yale.edu

Received

11 September 2003

Accepted

16 September 2004

\begin{abstract}
Objective: This study examined the impact of smoking, quitting, and time since quit on absences from work.

Methods: Data from the nationally representative Tobacco Use Supplements of the 1992/93, 1995/96, and 1998/99 Current Population Surveys were used. The study included full time workers aged between 18-64 years, yielding a sample size of 383778 workers. A binary indicator of absence due to sickness in the last week was analysed as a function of smoking status including time since quit for former smokers. Extensive demographic variables were included as controls in all models.

Results: In initial comparisons between current and former smokers, smoking increased absences, but quitting did not reduce them. However, when length of time since quit was examined, it was discovered that those who quit within the last year, and especially the last three months, had a much greater probability of absences than did current smokers. As the time since quitting increased, absences returned to a rate somewhere between that of never and current smokers. Interactions between health and smoking status significantly improved the fit of the model.

Conclusions: Smokers who quit reduced their absences over time but increase their absences immediately after quitting. Quitting ill may account for some but not all of this short run impact.
\end{abstract}

$\mathrm{T}$ here is substantial evidence that smoking hurts lifetime worker productivity through additional morbidity, early mortality, and other pathways. ${ }^{1-3}$ However, there is little evidence of the impact of smoking cessation on productivity in general and on absences specifically. Such evidence would be important in the decisions by firms to support cessation programmes, could influence governmental programmes, and may sway a smokers' decision to quit.

This study examined potential worker absences caused by smoking and quitting using the Tobacco Use Supplement (TUS) of the Current Population Survey (CPS). The TUS is a large, comprehensive and nationally representative sample covering many years. The analysis compared former to current smokers and examined time elapsed since quitting. Quitting was the focus because evidence that smoking is associated with absences does not automatically establish that quitting will lower days absent.

Absences were used as a measure of short term gains (or losses) to the firm. This aspect of productivity was used, as opposed to the longer term measures of productivity such as early mortality, since short term outcomes would be more likely to motivate change by the smoker, a firm or even the government, given budget constraints. Short term gains would be relevant to firms since worker turnover may reduce the payoff of longer term investments in worker health. Workers could also be more interested in short term gains.

\section{Smoking and absences}

Several pathways exist for smoking to cause increased absence from work. First, smoking may affect absences through increased health problems, especially respiratory, circulatory, and cancer. These health problems could result in days lost because of sickness and also more doctors visits and hospitalisations. ${ }^{4}$ Second, even before onset of these diseases, smokers' lungs and immune system may be compromised and they may be more tired or not feel well enough to go to work. Third, smoking is associated with more accidents and injuries, ${ }^{56}$ which could also result in lost days from work. Burns and fire related accidents are more likely among smokers as compared to non-smokers. ${ }^{78}$ Fourth, disutility from conforming to worksite clean air restrictions may also increase absences. Lastly, secondhand smoke may result in greater respiratory problems for family members of smokers, ${ }^{4}$ increasing days absent because of caring for family members.

Several studies indicate that smokers are more likely to be absent as compared to non-smokers. ${ }^{9-20}$ However, most of these studies have important limitations such as: small sample sizes, ${ }^{13}{ }^{1719-21}$ or samples that reflected a limited segment of the population. ${ }^{12-14}{ }^{16-20}$ Those with national data and more sophisticated methods have somewhat contradictory findings concerning the impact of current smoking on absences, ranging from negligible, ${ }^{11}$ to quite substantial losses (ranging from $11 \%$ for women to $59 \%$ for men). ${ }^{12}{ }^{15}$ Importantly, only two of these studies delineate former and current smokers. ${ }^{14}{ }^{18}$ None address the issue of gains to quitting. Moreover, none of the studies examine the impact of time since quit.

\section{Quitting and absences}

There is little empirical evidence as to the impact of quitting on absences. However, there are several reasons why quitting may reverse some of the adverse impacts of smoking on absences. Lowering the incidence of accidents, injuries, and fires may result in immediate reductions in absences. General health may improve and specific diseases may subside over time. ${ }^{22}$ The health of other family members may also improve over time as secondhand smoke exposure declines. On the other hand, the quitting process is arduous and withdrawal can be difficult to manage. ${ }^{23}$ The mental and physical hardships of quitting could increase absences. As a consequence, the net impact of quitting on absences and the timing of any effects are ultimately an empirical issue. Previous studies have either lumped former smokers into non-smokers, or treated recent quitters as smokers. Moreover, previous studies have failed to estimate the gains to quitting and may have produced biased estimates of smoking on absences.

Abbreviations: CPS, Current Population Survey; PSU, primary sampling unit; TUS, Tobacco Use Supplement 


\section{METHODS \\ Data}

Data for the analyses came from the TUS to the CPS, a large, nationally representative survey. The CPS is a monthly household survey conducted by the Bureau of the Census for the Bureau of Labor Statistics. It is used by the US federal government to provide statistics on employment and unemployment rates by demographic and geographic groups. These data are publicly available on the internet (http:// www.bls.gov/cps/). The CPS has detailed information on labour market aspects such as labour market participation, wages, occupation, industry, and other measures and also includes detailed socioeconomic and demographic characteristics.

With funding from the National Cancer Institute, the TUS was appended to the CPS starting in September of 1992. This survey was fielded again in January and May of 1993 , September 1995, January and May of 1996, September 1998, and January and May of 1999. All CPS respondents 15 years of age or older were eligible to participate in the TUS. Individuals were asked about their current cigarette smoking status, smoking and quit history, and use of other tobacco products.

The CPS is a monthly, multistage, stratified sample of approximately 57000 housing units from 729 sample areas. Roughly 150000 individuals are surveyed. As of the January 1996, the sample was reduced to about 50000 households, 130000 individuals and 754 primary sampling units (PSUs). The sampling involved dividing the USA into PSUs - most of which comprise a metropolitan area, a large county, or a group of smaller counties. Households were interviewed once a month for four months and then again in the same four months of the following year. This rotation scheme fully upholds the scientific tenets of probability sampling, so that each month's sample produces a true representation of the target population while limiting the undue reporting burden expected of respondents. Moreover, the spacing of the TUS yields independent samples.

\section{Sample}

Only full time workers who were between 18 and 65 years old were used in the analysis. The sample was limited to those between the ages of 18 and 65 because of the high rates of employment between those ages. Full time workers ( 35 hours a week or more) were chosen so that the absence data and behaviour had a standardised meaning across workers. That is, a smoker, or quitter, who works only part-time, could have a different absence pattern due solely to their ability to substitute hours across days and times not scheduled to work The remaining sample contained 383778 observations.

\section{Matching}

The TUS itself did not contain information on health status, a potentially important factor for the study of absences. Starting in 1996, the March CPS collected self reported excellent, good, fair, or poor health status. Disability status was also reported. To obtain the health information, observations in the TUS were matched to the March CPS survey using the unique individual identification that linked the CPS and the TUS. The match was straightforward since the IDs used in each survey were identical for the same person.

Given the CPS sample structure, the January and May TUS of 1996 and 1999 could be matched to the March survey of the same year. However, the September TUS could not be matched. Because the health question was not asked before 1996, only four out of the nine supplements could be matched, resulting in 71824 matched observations. This smaller matched sample contained data on individuals' smoking history as well as their health and disability status and employer sponsored health insurance coverage. The subsample was quite large and unlikely to be a biased sample because the matching/selection process was random.

\section{Measures}

\section{Dependent variable}

Data were available on the number of days missed from work in the last week and the cause of absences. This study focused only on absences caused by illness as the type of absence most likely to be related to smoking. A binary indicator of any days absent because of sickness last week was the primary dependent variable. Because of the large mass of responses on zero days missed, the number of days lost was not considered as a primary outcome. Understanding who had any day absent is the most critical issue, particularly since days lost in a week also contain an upper bound. About 2.6\% of the fulltime workers were absent any time in the last week because of sickness. Previous studies on the accuracy of self reports of absences have found that workers accurately report the number of days that they lost work because of sickness. ${ }^{24}$

\section{Smoking}

The TUS asked whether the respondent was a current smoker, a former smoker, or a never smoker. In this national sample of workers, over $54 \%$ of the sample never smoked, over $25 \%$ were current smokers, and about $21 \%$ were former smokers (see the first line of table 1). These numbers are similar to other estimated national averages. ${ }^{25}$ Former smokers were also asked when they quit, allowing calculation of the length of time since quit. Several alternative sets of smoking variables were used in the regressions. First, the categorisation of never, current, and former smokers was analysed. Then, in separate regressions, former smokers were delineated into time since quit. "Time since quit" was divided into eight categories: quit within the past 3 months, 3-6 months, 6-9 months, 9-12 months; and quit 1-4, 5-9, 10-14, or 15 years plus ago. Those with some missing information on their quit history were categorised as "former unspecified". Lastly, the detailed former smoker categories were compressed into two categories: (1) those who quit less than a year ago, and (2) those who quit a year or more ago.

\section{Control variables}

A variety of other factors that might have affected days absent from work were included in the analyses. Key control variables and their means are displayed in table 1 and are largely self explanatory. The average age in this sample was 39 years, over $90 \%$ had a high school education, $63 \%$ were married, and almost $80 \%$ were white. An appendix displays the full set of control variables used in the regressions (to view the appendix visit the Tobacco Control website-http:// www.tobaccocontrol.com/supplemental). As noted above, for the sub-sample that was matched to the baseline CPS information, health measures were available. These were self reported health status (excellent, very good, good, fair and poor) and disability status. As shown in the bottom panel of table $1,5 \%$ of the sample reported poor or fair health, while $36 \%$ reported excellent health, and $2 \%$ reported a disability.

\section{Analyses}

Using the sample of those working fulltime, the probability of having a day lost from work last week was estimated as a function of smoking status, health, and relevant work and demographic variables using logistic regression. As a robustness check, two different samples were used. The first sample was the entire TUS sample of workers. The other was the sample for which information about health status and health insurance was available by matching the March CPS to the 
Table 1 Summary statistics (CPS-TUS, 1992-1999)

\begin{tabular}{|c|c|c|c|c|}
\hline & All & Never smoker & Current smoker & Former smoker \\
\hline \multicolumn{5}{|l|}{ TUS sample } \\
\hline$n(\%)$ & $383778(100)$ & 207924 (54) & $96266(25)$ & $79588(21)$ \\
\hline Absent in past week (\%) & 2.6 & 2.2 & 3.3 & 2.8 \\
\hline Female (\%) & 43 & 47 & 40 & 36 \\
\hline Married-sp present (\%) & 63 & 63 & 55 & 73 \\
\hline With child under $6(\%)$ & 20 & 22 & 19 & 17 \\
\hline Mean age (years) & 39 & 38 & 39 & 44 \\
\hline \multicolumn{5}{|l|}{ Age distribution (\%) } \\
\hline Under 30 years & 22 & 26 & 23 & 10 \\
\hline $30-50$ years & 58 & 57 & 60 & 57 \\
\hline 50 or more years & 20 & 17 & 17 & 33 \\
\hline \multicolumn{5}{|l|}{ Education (\%) } \\
\hline Less than HS & 10 & 8 & 15 & 8 \\
\hline HS diploma & 34 & 30 & 44 & 33 \\
\hline Less than college & 28 & 27 & 28 & 29 \\
\hline College degree & 29 & 35 & 14 & 30 \\
\hline \multicolumn{5}{|l|}{ Race/ethnicity (\%) } \\
\hline White & 80 & 76 & 83 & 87 \\
\hline Black & 8 & 10 & 8 & 5 \\
\hline Hispanic & 7 & 9 & 6 & 5 \\
\hline Other race & 4 & 5 & 4 & 3 \\
\hline \multicolumn{5}{|l|}{ Occupation type (\%) } \\
\hline White collar & 60 & 65 & 48 & 63 \\
\hline Service occupation & 10 & 10 & 13 & 8 \\
\hline Blue collar & 27 & 22 & 37 & 27 \\
\hline Armed forces & 3 & 3 & 3 & 3 \\
\hline \multicolumn{5}{|l|}{ Matched health sample } \\
\hline n (\%) & $71824(100)$ & $40055(56)$ & $17122(24)$ & $14647(20)$ \\
\hline \multicolumn{5}{|l|}{ Health status (\%) } \\
\hline Poor/fair & 5 & 4 & 7 & 5 \\
\hline Good/very good & 59 & 56 & 66 & 60 \\
\hline Excellent & 36 & 39 & 27 & 35 \\
\hline Disabled & 2 & 2 & 3 & 3 \\
\hline \multicolumn{5}{|c|}{$\begin{array}{l}\text { Data are from the US Department of Commerce, Census Bureau, National Cancer Institute Sponsored Tobacco Use } \\
\text { Supplement to the Current Population Survey, } 1992-1999 \text {. } \\
\text { The matched health sample refers to a roughly } 1 \text { of } 6 \text { random sub-sample for whom extended survey data on } \\
\text { health status were available. } \\
\text { HS, high school; sp, spouse. }\end{array}$} \\
\hline
\end{tabular}

TUS by respondent ID. This is referred to as the matched TUS-CPS health sample or simply the "matched" sample. The TUS had the advantage of its bigger size, while the matched sample allowed health to be included as a control. Results were compared across samples and with and without the additional controls in order to judge the reasonableness of using the full TUS sample for extended analysis of time since quit without controls for health status and disability.

Further specifications were explored that included interactions between (1) smoking status and age, (2) smoking status and health status, and (3) smoking status and health and age. Likelihood ratio tests were used to compare model fit across specifications.

\section{RESULTS}

\section{Former versus current smoking}

Table 2 presents estimates of the impact of smoking status on having missed a day of work. The first set of columns displays the odds ratio and $\mathrm{p}$ value on the smoking status variables for the full TUS sample of 383778 observations. The second and third sets of columns report the regression results using the smaller matched health sample, but only the third set actually includes the self rated health status and disability as additional covariates. These columns can be compared to see how much of the change in coefficients is due to the different sample as opposed to the inclusion of the health status variables.

Table 2 Logistic regression of absence in last week on smoking status (current, former, never)

\begin{tabular}{|c|c|c|c|c|c|c|c|c|c|}
\hline & \multicolumn{3}{|c|}{ TUS sample ( $n=383778$ ) } & \multicolumn{6}{|c|}{ Matched health sample $(n=71824$ ) } \\
\hline & $\overline{O R}$ & (a) & (b) & $\overline{\mathrm{OR}}$ & (a) & (b) & OR & (a) & (b) \\
\hline Never smoker & 1.000 & & & 1.000 & & & 1.000 & & \\
\hline Current smoker & 1.368 & 0.000 & NA & 1.430 & 0.000 & NA & 1.352 & 0.000 & NA \\
\hline Former smoker & 1.330 & 0.000 & 0.322 & 1.360 & 0.000 & 0.042 & 1.321 & 0.000 & 0.710 \\
\hline
\end{tabular}

Data are from the US Department of Commerce, Census Bureau, National Cancer Institute Sponsored Tobacco Use Supplement to the Current Population Survey, 1992-1999.

The matched health sample refers to a roughly 1 of 6 random sub-sample for whom extended survey data on health status were available.

Health status controls are a set of five dummy variables for self reported health status (fair, poor, good, very good, excellent) and a dummy for disability status. All models also control for age, education, race, ethnicity, marital status, number of children, occupation, industry, metropolitan statistical area, state, and month/ year.

Column (a) displays the $\mathrm{p}$ value for the test of significance of the odds ratio (OR) relative to the referent "never smoker".

Column (b) displays the $\mathrm{p}$ value for the test of equality between the indicated OR and "current smoker".

NA, not applicable. 
Table 3 Logistic regression of absence in last week on smoking status (extended time since quit)

\begin{tabular}{|c|c|c|c|c|c|c|c|c|}
\hline & \multicolumn{4}{|c|}{ TUS sample $(n=383778$ ) } & \multicolumn{4}{|c|}{ Matched health sample $(n=71824)$} \\
\hline & $\mathbf{n}$ & OR & (a) & (b) & $\mathbf{n}$ & OR & (a) & (b) \\
\hline Never smoker & 207924 & 1.000 & & & 40055 & 1.000 & & \\
\hline Current smoker & 96266 & 1.371 & 0.000 & NA & 17122 & 1.353 & 0.000 & NA \\
\hline Quit $0-3$ months ago & 2494 & 3.26 & 0.000 & 0.000 & 501 & 2.634 & 0.000 & 0.000 \\
\hline Quit 3-6 months ago & 1468 & 1.499 & 0.005 & 0.535 & 298 & 1.178 & 0.616 & 0.673 \\
\hline Quit 6-9 months ago & 1531 & 1.906 & 0.000 & 0.010 & 279 & 1.874 & 0.025 & 0.247 \\
\hline Quit 9-12 months ago & 635 & 1.584 & 0.035 & 0.509 & 84 & 2.987 & 0.011 & 0.066 \\
\hline Quit $1-4$ years ago & 12395 & 1.338 & 0.000 & 0.666 & 2182 & 1.168 & 0.219 & 0.253 \\
\hline Quit 5-9 years ago & 11755 & 1.216 & 0.001 & 0.048 & 1973 & 1.233 & 0.106 & 0.481 \\
\hline Quit 10-14 years ago & 10860 & 1.205 & 0.003 & 0.044 & 2013 & 1.492 & 0.001 & 0.425 \\
\hline Quit $15+$ years ago & 21678 & 1.237 & 0.000 & 0.033 & 4286 & 1.293 & 0.007 & 0.643 \\
\hline Former smoker unsp & 16772 & 1.173 & 0.003 & 0.005 & 3031 & 1.063 & 0.614 & 0.051 \\
\hline Includes health controls? & No & & & & Yes & & & \\
\hline \multicolumn{9}{|c|}{$\begin{array}{l}\text { Data are from the US Department of Commerce, Census Bureau, National Cancer Institute Sponsored Tobacco Use Supplement to the Current Population Survey, } \\
1992-1999 . \\
\text { The matched health sample refers to a roughly } 1 \text { of } 6 \text { random sub-sample for whom extended survey data on health status were available. } \\
\text { Health status controls are a set of five dummy variables for self reported health status (fair, poor, good, very good, excellent) and a dummy for disability status. } \\
\text { All models also control for age, education, race, ethnicity, marital status, number of children, occupation, industry, metropolitan statistical area, state, and month/ } \\
\text { year. } \\
\text { Column (a) displays the p value for the test of significance of the odds ratio (OR) relative to the referent "never smoker". } \\
\text { Column (b) displays the p value for the test of equality between the indicated OR and "current smoker". } \\
\text { "Former smoker unspecified" refers to former smokers for whom length of time since quit was indeterminable. }\end{array}$} \\
\hline
\end{tabular}

The results confirmed that being a current smoker was associated with a significant increase in the probability of being absent. It was estimated that the odds of absence for smokers were about $35-43 \%$ more than never smokers. Odds of absence for former smokers were about $32-36 \%$ more than never smokers. Somewhat surprisingly, although both smoking status variables significantly increased the probability of missing a day of work because of illness, these coefficients were not statistically different from each other.

Results for the matched sample (middle three columns) were qualitatively similar to those for the full TUS sample (first three columns). Adding health and disability status also did little to change the main results (last three columns). The odds ratios for "current" versus "former" versus "never" from the TUS sample and the matched health sample were very similar for the samples of all, females and males. Since the first two regressions used the same set of covariates, this simply tested whether the samples themselves were different. In the third regression, inclusion of the health variables did not change the magnitude or levels of significance of the coefficients. Thus, in the expanded analyses of time since quit, emphasis was placed on the full TUS sample results since these provided the greatest power. As no significant differences were detected, results for males and females were combined throughout.

\section{Time since quit}

To investigate the issue of gains to quitting further, models were estimated to examine the length of time since the individual quit and its impact on absences.

Results for the full TUS sample gave the largest cell sizes for the quitting variables, so it was for this sample the most precise estimates were expected. These results are shown in the first columns of table 3. The significance levels in the upper part of the table indicate whether each coefficient was significantly different from never smokers, the omitted category. Since benefits to quitting imply a difference in the coefficients between current smokers and former smokers, tests were also conducted for current smokers versus each of the time since quit categories. The column labelled (b) in each regression grouping indicates the level of significance for the test of equality of effects between that category and current smokers.

In general, the time since quit analysis revealed a pattern of immediate and significant adverse consequences of quitting, with the benefits of quitting starting to accrue after a year. Specifically, those who quit within the last three months had the greatest likelihood of having an absence. Current smokers had a significantly 37\% greater likelihood of having missed a day, while those who quit in the last three months had $226 \%$ greater likelihood as compared to never smokers $(p<0.001)$. The magnitude of the impact then declined over time; smokers who quit 15 years ago or more were $24 \%$ more likely to have absences $(p<0.001)$. Those whose quit length was unspecified had only a $17 \%$ greater likelihood of absence compared to never smokers $(p<0.003)$. Thus, over time, those who quit were more likely to have absences as compared to never smokers, but less likely than current smokers. Figure 1 shows this relationship graphically. In this regression, all of the impacts as compared to the never smokers were significant. As seen in the bottom of table 3, six out of nine of the differences between current and former smokers were significant. The lack of significance in the other categories may be due to the relatively small sample sizes. The findings reveal that at first, quitters were significantly more likely to have an absence as compared to current smokers. After one year, quitters were less likely to have an absence as compared to current smokers, but it was not until after five years that the difference became significant.

To test for robustness, several alternative specifications were estimated. In all cases, the same qualitative pattern held for comparisons of former versus current and when examining time since quit. Alternative specifications included the following comparisons: (1) by sex; (2) absence last week from all causes as compared to absences caused by sickness only; (3) hours lost last week as compared to probability of an absence; (4) absences caused by sickness averaged over the last four months (available for a smaller sub-sample); (5) absences from any cause averaged over the last four months; and (6) absences last week caused by sickness controlling for intensity of smoking for everyday smokers (years the individual was an everyday smoker and quantity smoked everyday).

\section{Health and smoking status interactions}

It is possible that those who quit recently had quit because of poor health. ${ }^{26-29}$ In this case, it would be the ill health that caused both the higher probability of an absence as well as 


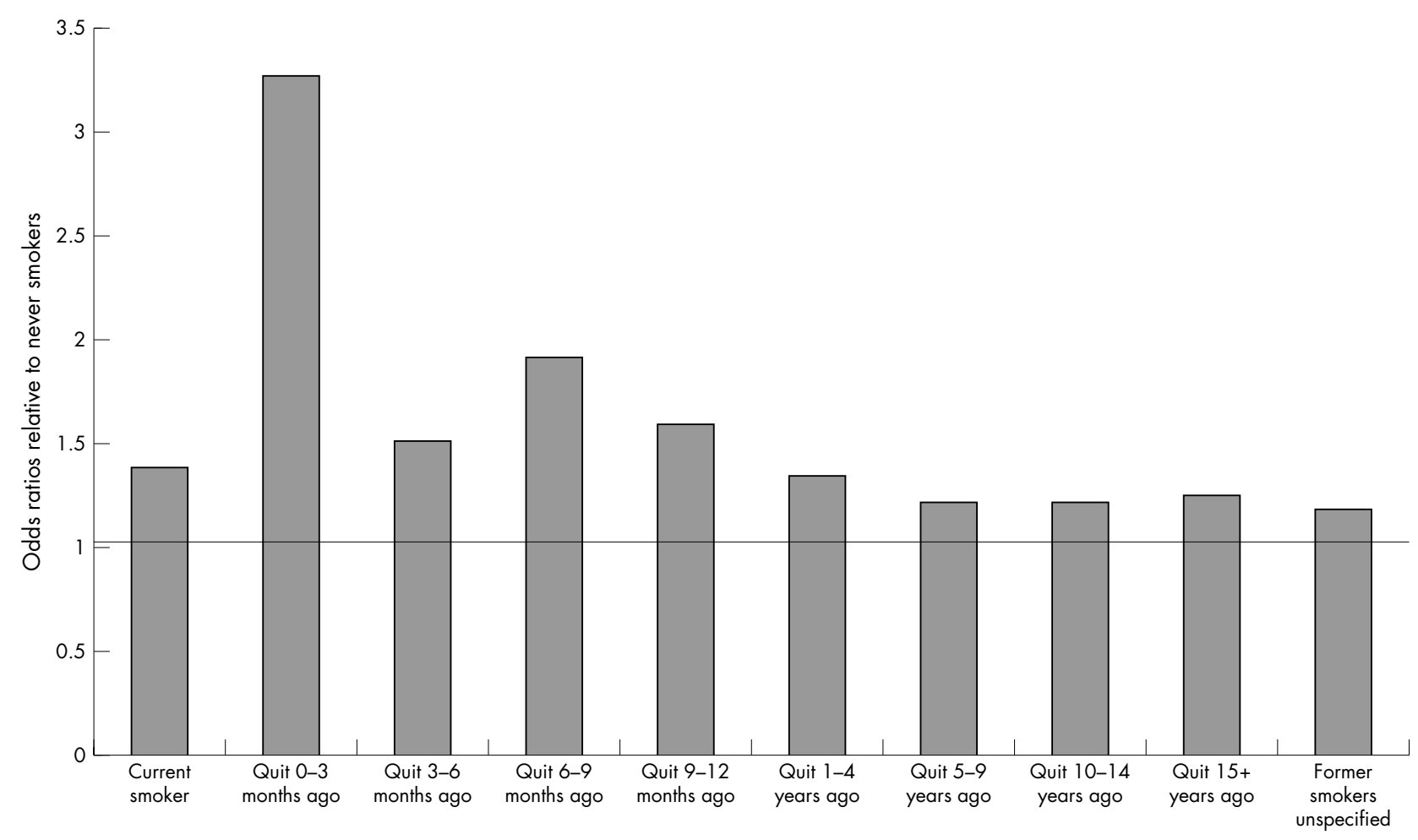

Figure 1 Odds ratios of absence relative to never smokers.

\begin{tabular}{|c|c|c|c|c|}
\hline & \multicolumn{4}{|c|}{ Matched health sample ( $n=71824)$} \\
\hline & $\mathbf{n}$ & OR & p Value & \\
\hline \multicolumn{5}{|l|}{ Health main effects } \\
\hline Fair/poor & 3643 & 1.000 & & \\
\hline Good/very good & 42652 & 0.477 & 0.000 & \\
\hline Excellent & 25529 & 0.293 & 0.000 & \\
\hline & $\mathrm{n}$ & OR & (a) & (b) \\
\hline \multicolumn{5}{|c|}{$\begin{array}{l}\text { Smoking effects by health } \\
\text { Fair/poor health }\end{array}$} \\
\hline Current & 1182 & 1.061 & 0.672 & NA \\
\hline Quit $<1$ year ago & 58 & 3.079 & 0.001 & 0.002 \\
\hline Quit 1 year & 554 & 1.021 & 0.908 & 0.841 \\
\hline Never smoked & 1662 & 1.000 & & \\
\hline \multicolumn{5}{|l|}{ Good/very good health } \\
\hline Current & 11250 & 1.268 & 0.000 & NA \\
\hline Quit $<1$ year ago & 704 & 1.978 & 0.000 & 0.008 \\
\hline Quit 1 year & 6235 & 1.325 & 0.000 & 0.606 \\
\hline Never smoked & 22616 & 1.000 & & \\
\hline \multicolumn{5}{|l|}{ Excellent health } \\
\hline Current & 4691 & 1.935 & 0.000 & NA \\
\hline Quit $<1$ year ago & 400 & 2.020 & 0.012 & 0.880 \\
\hline Quit 1 year & 3667 & 1.320 & 0.035 & 0.007 \\
\hline Never smoked & 15873 & 1.000 & & \\
\hline
\end{tabular}

Data are from the US Department of Commerce, Census Bureau, National Cancer Institute Sponsored Tobacco Use Supplement to the Current Population Survey, 1992-1999.

The matched health sample refers to a roughly 1 of 6 random sub-sample for whom extended survey data on health status were available. Four smoking status indicators were interacted with three categories of health status to generate results.

All models also control for age, education, race, ethnicity, marital status, number of children, occupation, industry, metropolitan statistical area, state, and month/year.

Column (a) displays the $p$ value for the test of significance of the odds ratio (OR) relative to the referent "never smoker".

Column (b) displays the $\mathrm{p}$ value for the test of equality between the indicated OR and "current smoker". the quitting. To investigate this possibility of the "quitting ill" effect, regressions were estimated interacting health status with smoking status. These regressions help to understand whether those who were in poor health and thus quitting ill were those who had the higher probability of absence. Based on the finding from the detailed time since quit regressions that those who had stopped smoking a year or more ago had lower absences than current smokers, former smokers were pooled into two categories, those who quit within the last year and those who quit a year or more ago. The advantages to pooling include larger sample sizes, and thus greater precision in the estimates, and ability to estimate coefficients on interactions between health and quitting.

Table 4 displays the variables of interest-the full set of interactions among health status (fair/poor, good/very good, excellent health) and the four smoking status variables. All coefficients for this regression are presented in the appendix. Additional interactions with age and smoking status, and age by health by smoking status, were estimated but these did not significantly improve the fit of the model.

Examining the health/smoking status interactions provides insights into the quitting ill hypothesis. Not surprisingly, the main effects of the health status variables are significant, indicating that those with better self reported health status had a lower likelihood of being absent. For excellent health, the odds ratio is 0.29 as compared to those in poor health.

The interactions between health and the four smoking status variables reveal a more complicated picture. Those who have quit recently and who report fair/poor health are those most likely to have quit sick. Thus, it would be expected for this group to have a higher probability of absence than recent quitters in the better health categories. The analysis confirms this hypothesis, with this group having the highest odds ratio relative to never smokers of the same health type (odds ratio (OR) 3.08). This group has a significantly higher probability of being absent even as compared with current smokers in 
poor/fair health (OR 1.061). While recent quitters in the other health categories still had relatively higher rates of absence, the odds ratios were not of the same magnitude as those in fair/poor health. Recent quitters in good/very good health had twice the odds of absence as never smokers in good/very good health and recent quitters in excellent health had twice the odds of absence as never smokers in excellent health. However, these were not significantly different from the effects for recent quitters in fair/poor health. So, these findings seem to provide some support for the quitting ill hypothesis, but also support the finding of a larger probability of absences for recent quitters irrespective of health status as witnessed by the higher rates of absence for these recent quitters within each of the three health categories.

Generally, the odds ratios on long term quitters are difficult to interpret because health is measured as current status and quitting occurred at least a year or more ago. The difference between the coefficient on current smokers and long term quitters is not significant for those in fair/poor health. It is also interesting to note that for current smokers in fair or poor health, there is no increased likelihood of absence relative to never smokers in poor or fair health. This may reflect the complex relation between smoking and healththat is, some of the effect of being a current smoker is captured through the main effect of the self reported health variable.

When evaluating the set of odds ratios for those reporting excellent health interacted with the four quit variables, it is important to remember the overall low probability of absences for those in excellent health. The odds ratio for current smokers in excellent health relative to never smokers is 1.94 compared to 1.32 for long term quitters relative to never smokers. For those in excellent health, there seem to be significant gains to quitting long term. Note, however, that there is still no difference between current smokers and recent quitters in this group.

\section{DISCUSSION}

Current smoking increased the probability of being absent a day in the last week relative to never smokers. However, both current and former smokers, on average, had higher probabilities of being absent and there were no significant differences between these two groups. Thus, a naïve analysis would conclude there are no gains to quitting. This suggested that preventing smoking initiation is beneficial but that quitting is not with respect to absences. Yet, this finding seemed contradictory to the evidence that health improves over time with quitting. ${ }^{22}{ }^{30}$ One explanation could be that health status is confounding the relationship. Yet, including self reported health and disability status (albeit in a limited sample) did not change this result. Further, the inclusion of smoking/health status interactions revealed a similar pattern for those in poor health.

It was found that it was critical to include a series of time since quit variables. These clearly indicated an immediately greater probability of absence followed by future gains to quitting. Those who maintained their cessation for some time had significantly lower absences than current smokers. The finding of a significant, immediate increase in absences is consistent with evidence on quitting and use of medical care; medical expenses increase in the first year post-quit and then decline to below the expenses of current smokers. ${ }^{31} 32$

That individuals are quitting ill would be a competing hypothesis. However, while there are some results that could be consistent with this hypothesis, even for those in poor health recent quitters have a higher probability of being absent as compared to current smokers. One explanation is that self reported health status does not adequately capture

\section{What this paper adds}

Studies indicate that smokers are more likely to be absent from work as compared to non-smokers. However, several of these studies have important limitations including small, nongeneralisable samples and weak statistical methods. There are only a few that use national data and more sophisticated methods. These have somewhat contradictory findings. Only a couple of extant studies on absences delineate former and current smokers. The broader set of studies on smoking and productivity indicate that smoking reduces productivity through greater morbidity and early mortality, but does not focus on the gains to quitting.

This study adds to the literature in several ways. First, it uses data from a large, nationally representative sample and includes data from several years. Thus, the conclusions can be generalised to the nation, not confined to a small, specialised sample. Second, this study investigated whether former smokers have reduced absences as compared to current smokers.

Additionally, it is the first study to quantify the impact of cessation on absences by time elapsed since quitting. It also produced policy relevant data. Absence from work was chosen as the primary dependent variable since it is a measure of productivity loss that is immediately felt by both workers and firms and thus may motivate change.

all differences in health. Another possible explanation is that there is a set of smokers who quit and then relapse shortly and who are disproportionately in the category of recent quitters. They may be systematically more likely to have absences as compared to other quitters. This suggests an important area for further research.

\section{Limitations}

Smokers and quitters may differ from never smokers in ways that make them more likely to be absent. This study attempted to control for such potential differences by including relevant control variables. However, there may be some unobserved heterogeneity by smoking status. For example, no controls were available for alcohol consumption, other health habits, and personality differences. However, examining former as opposed to current smokers helps to overcome the problem of self selection into smoking. If smokers self select into smoking for reasons that are not observable, comparisons among those that once smoked helps to mitigate this initial self selection issue. The use of longitudinal data would help to overcome some of these problems. However, a long time frame and a very large sample would be needed to allow precise estimation of these relationships. The large dataset is needed to obtain sufficiently large cells sizes on years since quit.

Another issue is that the CPS did not ask specific questions regarding paid sick leave. Also, there may be unmeasured impacts of health on both absences and quit behaviour. Information on specific chronic conditions may be relevant but are not available in the TUS/CPS.

Use of only a binary indicator of whether or not there was an absence last week caused by sickness is a limitation. This measure ignores the magnitude of the absence (hours missed), may be suspect because of the use of a one week only measure, and focuses only on absences caused by sickness. However, the reported robustness checks on all of these items found that the pattern remains the same. 


\section{Implications}

These results have implications for public and private policy regarding smoking cessation. Based on these findings, firms with high turnover would be especially unlikely to gain in terms of absences averted from smoking cessation programmes, holding other factors constant. Thus, they may be less likely to implement workplace smoking bans, offer smoking cessation programmes, or cover treatment for cessation. Note, however, that by examining reduced absences, only a small part of the potential total worksite gains to quitting were measured. Other studies have estimated the larger realm of potential gains to quitting and have found that the benefits outweighed the potential costs. ${ }^{33}{ }^{34}$ Additional considerations could include: increases in other aspects of productivity (for example, higher output per hour and fewer work breaks) and the reductions in medical care costs. The precise distribution of potential benefits over time would have to be carefully examined to estimate the time frame for payback of cessation programmes and would be useful for cost effectiveness analyses. The long run gains suggest that there would be potential productivity gains to workers and to society at large from cessation. Workers may therefore invest in cessation on their own. To reap the productivity gains, governments could mandate cessation coverage by health insurance, provide coverage fully in Medicaid and Medicare, or directly support cessation programmes.

Another implication of these findings relates to treatments for cessation. Since most smokers quit or attempt to quit without the aide of professional or pharmacological help, ${ }^{35}$ there may be potential for cessation aides to ameliorate short run difficulties of quitting. Ultimately, it may pay for firms, and workers, to invest in higher quality cessation efforts. However, comprehensive cost benefit analyses of specific programs would be required.

\section{Conclusions}

Previous work on smoking and productivity had demonstrated the effect of smoking on absence from work. This study shows that not only are there costs to smoking in terms of absences, but that in the long run there are benefits to quitting. Meanwhile, in the short run (less than one year) quitters are more likely to have absences. There is some evidence that this is a "quitting ill" effect. The spike in absences for recent quitters was most pronounced for those in poor or fair health. Importantly, this is not necessarily what a firm would witness if a cessation program were implemented.

\section{ACKNOWLEDGEMENTS}

This research was supported by a grant from the Robert Wood Johnson Foundation (039787), as part of the Transdisciplinary Tobacco Use Research Center at Yale.

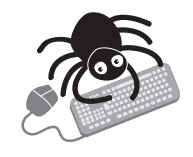

To view the appendix visit the Tobacco Control website-http://www.tobaccocontrol.com/ supplemental

\section{Authors' affiliations}

J L Sindelar*, T A Falba, S H Busch, Department of Epidemiology and Public Health at Yale University, New Haven, Connecticut, USA N Duchovny, Congressional Budget Office, Washington DC, USA

*Also National Bureau of Economic Research

\section{REFERENCES}

1 Centers for Disease Control and Prevention. Annual smoking-attributable mortality, years of potential life lost, and economic costs - United States, 1995-1999. MMWR Morb Mortal Wkly Rep 2002;51:300-3.

2 Bartecchi CE, MacKenzie TD, Schrier RW. The human costs of tobacco use (1). N Engl J Med 1994;330:907-12

3 Rice DP, Hodgson TA, Sinsheimer P, Browner W, et al. The economic costs of the health effects of smoking, 1984. Milbank Quarterly 1986;64:489-547.

4 US Department of Health and Human Services. Reducing the health consequences of smoking: 25 years of progress. A report of the Surgeon General, 1989. Rockville, Maryland: Public Health Service, Centers for Disease Control, Office on Smoking and Health, 1989 (DHHS Publication No (CDC) 89-8411.).

5 Reynolds KL, Heckel HA, Witt CE, et al. Cigarette smoking, physical fitness, and injuries in infantry soldiers. Am J Prev Med 1994;10:145-50.

6 Tsai SP, Cowles SR, Ross CE. Smoking and morbidity frequency in a working population. J Occup Med 1990;32:245-9.

7 Barillo DJ, Brigham PA, Kayden DA, et al. The fire-safe cigarette: a burn prevention tool. J Burn Care Rehabil 2000;21:162-4; discussion 164-70.

8 Leistikow BN, Martin DC, Milano CE. Estimates of smoking-attributable deaths at ages 15-54, motherless or fatherless youths, and resulting Social Security costs in the United States in 1994. Prev Med 2000;30:353-60.

9 Athanasou JA. Sickness absence and smoking behavior and its consequences. A review. J Occup Med 1975;17:441-5.

10 Athanasou JA, Reid CC, Ferguson DA. Sickness absence and smoking. Med J Austr 1981;1:211-2.

11 Ault RW. Smoking and absenteeism. Applied Economics $1991 ; 23(4 b): 743-54$.

12 Bertera RL. Behavioral risk factor and illness day changes with workplace health promotion: two-year results. Am J Health Promot 1993;7:365-73.

13 Hendrix WH, Taylor GS. A Multivariate analysis of the relationship between cigarette smoking and absence from work. Am J Health Promot 1987; 1(3):5-11.

14 Halpern MT, Shikiar R, Rentz AM, et al. Impact of smoking status on workplace absenteeism and productivity. Tobacco Control 2001;10:233-8.

15 Leigh JP. Smoking, self-selection and absenteeism. Quarterly Review of Economics and Finance 1995;35:365-86.

16 Parkes KR. Smoking as a moderator of the relationship between affective state and absence from work. J Applied Psychol 1983:68:698-708.

17 Parkes KR. Relative weight, smoking, and mental health as predictors of sickness and absence from work. J Applied Psychol 1987;72:275-86.

18 Robbins AS, Fonseca VP, Chao SY, et al. Short term effects of cigarette smoking on hospitalization and associated lost workdays in a young healthy population. Tobacco Control 2000;9:389-96.

19 Van Tuinen M, Land G. Smoking and excess sick leave in a department of health. J Occup Med 1986;28:33-5.

20 Yen LT, Edington DW, Witting P. Prediction of prospective medical claims and absenteeism costs for 1284 hourly workers from a manufacturing company. J Occup Med 1992;34:428-35.

21 Parrott S, Godfrey C, Raw M, et al. Guidance for commissioners on the cost effectiveness of smoking cessation interventions. Health Educational Authority. Thorax 1998;53(suppl $5 \mathrm{Pt}$ 2):S1-38.

22 Oster G, Colditz GA, Kelly NL. The economic costs of smoking and benefits of quitting for individual smokers. Prev Med 1984;13:377-89.

23 Hughes JR, Hatsukami D. Signs and symptoms of tobacco withdrawal. Arch Gen Psychiatry 1986;43:289-94.

24 Revicki DA, Irwin D, Reblando J, et al. The accuracy of self-reported disability days. Med Care 1994;32:401-4.

25 CDC. State-specific prevalence of current cigarette smoking among adults, and policies and attitudes about secondhand smoke - United States, 2000. MMWR Morb Mortal Wkly Rep 2001;50:1101-6.

26 Lando H, Hennrikus D, McCarty M, et al. Predictors of quitting in hospitalized smokers. Nicotine Tob Res 2003;5:215-22.

27 Martinson BC, O'Connor PJ, Pronk NP, et al. Smoking cessation attempts in relation to prior health care charges: the effect of antecedent smoking-related symptoms? Am J Health Promot 2003;18:125-32.

28 Osinubi OY, Afilaka AA, Doucette J, et al. Study of smoking behavior in asbestos workers. Am J Ind Med 2002;41:62-9.

29 Falba T. Health events and the smoking cessation of middle aged Americans. $J$ Behav Med (in press).

30 US Department of Health and Human Services. The health benefits of smoking cessation. A report of the Surgeon General, 1990. Rockville, Maryland: Public Health Service, Centers for Disease Control, Office on Smoking and Health, 1990 (DHHS Publication No (CDC) 90-8416).

31 Fishman PA, Khan ZM, Thompson EE, et al. Health care costs among smokers, former smokers, and never smokers in an HMO. Health Serv Res 2003;38:733-49.

32 Wagner EH, Curry SJ, Grothaus L, et al. The impact of smoking and quitting on health care use. Arch Intern Med 1995; 155:1789-95.

33 Warner KE, Smith RJ, Smith DG, et al. Health and economic implications of a work-site smoking-cessation program: a simulation analysis. J Occup Environ Med 1996;38:981-92.

34 Kristein MM. How much can business expect to profit from smoking cessation? Prev Med 1983; 12:358-81

35 Meyer GK, Baker T, Smith SS, et al. How smokers are quitting. In: Insights: smoking in Wisconsin. Madison, Wisconsin: University of Wisconsin Center for Tobacco Research and Intervention, 2003. 